\title{
Nonhumans in Participatory Design
}

11 April 2017

Author: Dr Louis Rice.

Member of the World Heath Organisation Collaborating Centre for Healthy Urban Environments

Department of Architecture, University of the West of England, Frenchay Campus, Coldharbour Lane, Bristol, BS16 1QY, UK.

Phone: +44 (0)117 3283014

Email: Louis.Rice@uwe.ac.uk

\begin{abstract}
This article examines the role that nonhumans play in participatory design. Research and practice concerned with participatory design mostly focuses on human participants, however nonhumans also participate in the design process and can play a significant role in shaping the process. This article focuses on how nonhumans participate in the design process. An empirical case-study is used to illustrate how humans and nonhumans assemble to form networks in order to effect a design. Nonhumans increase the level of participation in a design process. The case-study reveals how nonhumans help to maintain, destroy or strengthen networks by substituting, mediating and communicating with humans and often, in doing so, making human actors more or less visible in the process. Nonhumans play a part in configuring the social. Revealing the presence and roles of nonhumans is an important means through which to increase the democracy within the design process.
\end{abstract}

Keywords: participatory design, nonhumans, actor-network, urban design, tactical urbanism

\section{Introduction}

The research examines the process of participatory design in a community-garden. In the case-study, we see how: elderly residents, amateur gardeners, children and keen volunteers along with: spades, flowers, phones, fertilizers, coffee, barbeques, posters, bricks and mortar come together to form a network of human and nonhuman participants. Politics, environmentalism, society, aesthetics, technology, biodiversity and economics are assembled around the design and production of a communitygarden. Humans and nonhumans are participants in this network. Any network is an 
ongoing process - and just like a garden (and as any gardener will tell you), it needs constant maintenance. The network is a constant process of retaining, adding, or subtracting, seducing, enticing, deterring and/or enlisting participants.

This article explores the role of nonhumans in the process of participatory design. There has been a dearth of participatory design research that focuses on nonhumans despite the growth of work on nonhumans in other research fields. The literature review explores the two constituent parts: participation and design specifically in relation to nonhumans. The review begins by briefly defining what is meant by nonhuman participation in this context. As the notion of democracy is fundamental to participatory design, the inclusion of nonhumans into an account of democracy potentially challenges or critiques existing narratives. There is an examination of the implications and complications of adding nonhumans into accounts of democracy. Secondly, nonhumans in participatory design is a fledging concern and the article reviews literature that investigates the implications of nonhumans in relation to design. The key terms derived from this review are then applied to an empirical casestudy project and conclusions drawn. The research is focused on the interaction between humans and nonhuman; with this proviso, any nonhuman action that occurs without any correlation to human action is excluded from this research (which is not to underplay its importance generally, but it remains outside the scope of this research).

\section{Nonhuman participation defined}

Humans and nonhumans participate in a design process through their actions. One cannot participate if one does not act; equally, no action means no participation. Humans and nonhumans are actors; action can be carried out by anything that affects something else; or the effect one actor has on another. Actors are 'entities that do things' (Latour 1992, 241) with 'action itself being defined by a list of performances' (Akrich and Latour 1992, 259). Action is understood as an effect on another actor. Humans and nonhumans are capable of action. Objects that affect, interfere or intervene with a human actor are what Latour (1992) calls objects 'with sociology'. Without any human action, the object remains just an object; however when objects come into a relationship with a human, a new hybrid condition is formed. The collective of all these actors forms a network, in this context as a design team.

An important aspect of what is meant by 'participation' in participatory design is the breaking down of unnecessary or unhelpful boundaries. Removing the dichotomy between expert/non-expert has generated much of the impetus behind participatory design. In traditional (non-participatory) design, there is a key designer, and/or team of experts, who control the process (Rendell 2004). In participatory design, nonexperts become part of the design team. As users are experts of their own lived experiences, they can, when appropriately supported by the design team, also become the designers (Robertson and Simonsen 2012). Callon, Lascoumes, and Barthe (2011) propose that alliances of experts, non-experts, politicians, scientists and citizens participate in 'hybrid forums' to design and resolve complex issues. Participatory design is about altering the boundary between participating and 'not' participating (Akama 2015). Transgressing boundaries and expanding the definition of who (or what) participates as widely as possible; nonhumans come to be counted democratically. Haraway $(2000,157)$ describes how democracy is about 'the 
empowering of people who are involved in putting worlds together'. Worlds designed and composed from the entanglement of humans and nonhumans.

Nonhumans have been relatively under-researched in the discipline of participatory design (Palmas and Busch 2015; Tolbert et al. 2016). Where there has been some research on the role of nonhumans in participatory design, the focus tends to be more on the equipment and materials used as design tools, for example: pencils, paper, buttons, textiles, moss, weeds, computer modeling or other media (Akama 2015; Binder et al. 2015; Brandt et al. 2013; Craft 2013; Lindstrom and Stahl 2012; Müller 2007; Sanders 2000; Schoffelen et al 2015). There have been some attempts to include nonhumans as codesigners, for example: examining animals (birds) as 'codesigners' (Jönsson and Lensskjold 2015); memos and reports as meaning-makers in the design process (Tolbert et al. 2016); investigating a 'quisling' whose "agency is non-human" (Palmas and Busch 2015, 238) or as socio-technical collective of humans and nonhuman participants (Callon 2004). However, there is still a very clear dichotomy in participatory design between human participants on one side and nonhuman on the other (Andersen et al. 2015). Whilst the research focus here is principally on nonhumans in participatory design; going outside of this realm, there is more evidence of nonhumans being treated equally with humans. The field of design anthropology is more inclusive of the role of nonhumans in the design process (Gunn, Otto and Smith 2013). Practices, beliefs, cultures, materials, spaces and other issues are used in design anthropology to analyse and understand the design process (Anusas and Ingold 2013). Networks of humans and nonhumans have previously been examined, using different terminology, in a number of disciplines, for example: actor-network theory (Latour 2005a); assemblage (Law 2004) cyborgs (Haraway 1991); dispositif (Foucault 2002); or hybrids (Whatmore 2002). The germane issue being that nonhumans and humans enter into an alliance as a hybrid collective, wherein new identities are formed and performed (Callon 2004). There is a challenging of the relationship and distinction of humans and animals, particularly, more-than-human geographies (Alger and Alger, 1999; Bear and Eden 2011; Birke and Hockenhull 2012; Derrida, 2008; Fox, 2006; Haraway 2003 and 2008; Sayes, 2014). Serres (2007, 227-228) describes some nonhumans as 'quasi-objects, quasi subjects' because they have qualities that are common to both without fitting neatly into one category, and more importantly that nonhumans can posses subject-like characteristics; similarly, object-oriented ontologies question the boundaries between object and subject (Bryant 2011; Harman 2011); and the myriad interpretations and implications of posthumanism (Ferrando 2013; Herbrechter 2013; Nayar 2013; Coole and Frost 2010; Hayles 2008). Outside out the realm of participatory design there is a burgeoning wealth of research into nonhumans; partly concerning how nonhumans configure the social whether as part of a collective assemblage, or more fundamental questions over the boundary between objects and subjects, and the transgression of human and nonhuman identity and agency. Regardless of whichever philosophical or intellectual position, it is clear that humans and nonhumans need to be considered more holistically in order to develop a fuller understanding of (participatory) design.

\section{DEMOCRACY}

\section{Participation and democracy}


The inclusion of nonhumans as participants in the design process raises an issue that lies at the heart of the participatory design movement: democracy. Democracy is a central tenet of participatory design (Binder et al. 2015). Whilst democracy is clearly an important issue, trying to define what democracy means, in participatory design, is sometimes not entirely clear, or means different things depending on the context (Catt 1999). In the broadest sense, democracy is founded on the notion of equal participatory rights for all (Arblaster 1987). Everyone has the right to participate in matters that might affect them. There are many different variations in 'how' participation could occur, depending on the mode of democracy one chooses.

Callon, Lascoumes, and Barthe (2011) propose thinking about democracy by categorizing along two axes; composition, i.e. ' who' is in the public/group; and aggregation, i.e. 'how' democracy is enacted. The first axis concerns who constitutes the network. A composition that includes humans and nonhumans form an expanded set of 'participants'. In this sense, increasing participation is a means of democratizing the design process (Kensing and Blomberg 1998). Participatory design is intended to be 'by, with and for' the stakeholders (Kensing and Greenbaum 2012). Democratization of the participatory design process has involved increasing the number of human stakeholders and the quantity and quality of input from those stakeholders. Accepting nonhumans as participants in the design process necessarily widens the notion of participation and democratizes democracy (Callon, Lascoumes, and Barthe 2011). Latour (2005b) calls for 'making things public' as a means of democratizing matters of concern. This "object-oriented democracy" $(2005 \mathrm{~b}, 16)$ includes an assemblage of humans and nonhumans as part of a collective approach to contested design issues; participatory design as a mode of activism. Making things public refers partly to a broader ambition to make issues more visible as a mechanism for greater democracy in action (Storni 2015; Stuedahl and Smordal 2015; Callon, Lascoumes, and Barthe 2011). Schoffelen and Huybrechts (2013) explicate how making things public is a form of democracy in a number of ways: by opening up the debate to a more diverse population, enabling participation from a wider number of affected actors and revealing previously hidden or invisible issues. What is most important perhaps is the presence of humans or nonhumans in a particular context. Representation is important, that is: visibility itself is an important means of democratic participation. The corollary of this is that absence or invisibility implies a lack of participation. When a nonhuman is not present or invisible; it is not communicating. It signifies nothing because it is invisible, no longer seen or thought of. In Latourian terms; it is not acting, ergo it has no power. Bauman $(2004,34)$ explains the importance of visibility for matters of concern: 'we make them invisible by not looking and unthinkable by not thinking'. Visibility is a form of action, as Bauman suggests, it acts to stimulate the process of thinking. Humans or nonhumans who are invisible or absent are less likely to be, or become, participants in a design conversation. The physical presence of nonhumans, rather like direct democracy, is a mechanism through which nonhumans communicate and participate (Rice, 2013). Not everyone agrees that participatory design is necessarily democratic, nor that widening participation successfully resolves an issue. Palmas and Busch (2015) state the participatory design is not an entirely valid democratic process because it maintains the power relations already extant; particularly in the framing of the situation before participants become involved. Notwithstanding this criticism, participatory design can still be an effective and worthwhile process, as Churchill 
famously joked: 'democracy is the worst form of government, except for all the others'.

The second axis: aggregation concerns the mechanism/s through which participation occurs and how democracy is enacted. There are myriad forms of democracy: direct, delegated, popular, representative and participatory (among others) (Crick 2002; Held 2006; Habermas 2006; Rawls 2005) and all have been utilized in participatory design. Common to all these forms of democracy is a debate about decision-making process. Binder et al (2015) explain how decision-making, inherent in the design process, is necessarily a mode of democratic action. Participation is democracy in action (Stuedahl and Smordal, 2015). Decision-making can be arrived at through a process of consensus: discussion, dialogue, concord, entente and unanimity. Participatory design is communication between numerous actors that can be consensual, conciliatory and harmonious. The purpose of allowing more participants into the process and allowing the many to make decisions is precisely to avoid problems arising through poor communication or enforcing decisions on others. A democratic process ensures that everyone has the right to participate, though not necessarily to rule or have their way. Decision-making can be arrived at through a process of dissensus: arguments, disagreement, debates, misunderstandings, dissent and conflict (Ranciere 2015; Mouffe 2000). Callon, Lascoumes, and Barthe (2011:28) see conflict in a positive light and suggest that "controversies enrich democracy" by stimulating society to develop new resolutions. Whilst participatory design is often an attempt to reduce some of the conflict and contradictory aspects of the process, design inherently involves a power struggle where there will be winners and losers (Björgvinsson, Ehn, and Hillgren 2012; Palmas and Busch 2015). As Gore Vidal quips 'it is not enough to succeed - others must fail'. Participatory design involves the assembling of a successful consensual network of human and nonhuman actors (Callon 1986; Law 2009). During the participatory design process there are a series of actions that lead to the building of new networks and, equally importantly, the cutting of ties with other networks. Design can be seen as the interplay of these two directions; destructive or additive (Pedersen 2015) as well as simply maintaining the existing status quo. Some of these actions lead to new or strengthened associations with (human and nonhuman) actors to form a durable network whilst other actions lead to disassociations with actors to destroy networks (Callon and Law 1982).

\section{Participation through: substitution, mediation and communication}

Tracing the destruction and/or construction of networks illustrates how the process of design operates, as the most successfully assembled network becomes the finalized design proposal. 'How' nonhumans participate in the network can be categorised via three mechanisms: substitution, mediation and communication. That is nonhumans substituting for humans, nonhumans mediating humans or nonhumans communicating with humans. In the first process, an object can simply replace a human action through substitution; Latour (1992) cites the example of how an automatic door-closer substitutes for human action. A nonhuman takes the place of a human, and thereby renders action by a human unnecessary or redundant. Other mundane examples of substitution include: a speed bump (otherwise known as a sleeping-policeman) to replace a traffic warden for controlling cars or a lock to substitute for a human guard. There are many examples of automated nonhumans 
replacing human action particularly in the fields of: artificial intelligence, internet of things, smart cities and robotics (Ford, 2015). Secondly, a nonhuman mediates human behaviour (Law and Mol, 1995). For example a nonhuman might interact with a human to facilitate an action; for example a bench facilitates sitting; nonhuman objects configure a new relationship with human actions. A mobile phone enables connection between humans but frames and structures that dialogue, mediating between the two. Nonhumans participate as mediators of human action mostly clearly in the form of tools. Tools have played a vital part in human development (Ferraro and Andreatta 2011). Notably, until recently the use of tools was seen as a privilege and capacity exclusive to humans, but it is now accepted that animals also utilize tools. A tool is broadly defined as "a detached object that is controlled by the user to perform work" (Wynn: 2002:33). Latour goes further in his definition: "What then, is a tool? The extension of social skills to nonhumans" (Latour 1999:211). Thirdly, nonhumans are used as models, graphs and diagrams to communicate with humans. Nonhumans communicate in the process of design in a number of ways. Callon (1986) describes how the presence of scallops works akin to union members casting ballots in a vote; Latour and Woolgar (1986) portray how chemicals converse with scientists in the Salk Institute; Law and Mol (1995) explicate how blood vessels communicate to doctors about the health of their patient. Latour $(1987,72)$ describes how 'neutrinos that cannot talk, in principle, but are made to write, scribble and sign' as a direct mechanism for translation between nonhuman and human worlds. Nonhumans participate in design conversations through many modes of communication. Serres (1995) describes nonhumans as 'message-bearers' that communicate across disparate domains and act as a 'sign'. Semiotics, the study and meaning of signs, helps the understanding of how nonhumans communicate to humans. Eco $(1977,7)$ explains that 'semiotics is in principle the discipline studying everything which can be used in order to lie. If something cannot be used to tell a lie, conversely it cannot be used to tell the truth; it cannot in fact be used 'to tell' at all' (emphasis in original). Nonhumans participate in design conversations by telling humans messages and information; whether they are telling truths or lies is a moot point.

\section{DESIGN}

Design process: humans and nonhumans

Design is a 'conversation' (Lawson 2005). A conversation primarily between the members of a design team, but also between the media chosen through which to represent and manifest the conversation and the context in which that conversation takes place. The design process is an ongoing inter-communication between myriad actors (Schumacher 2016). The language of that conversation for humans is clear enough: discussions, thoughts, dialogue, conversations, arguments; which can be transcribed into or through: minutes, reports, diagrams, maps, models, sketches, agendas or other media (Sanoff 2005; Lindstrom and Stahl 2012; Sanders and Stappers 2008). The language of nonhumans is less familiar although it is evidently imbricated in various ways in the sketches, reports and models mentioned. Nonhumans play a part in this communication in a number of ways; partly through substituting humans and partly through mediating between humans and nonhumans. Design requires iterative translations across these two quite different worlds of 
communication, between human thought and the material world (Serres 1980; Tolbert et al. 2016). These two principal domains of design can also be understood as abstract thinking, a purely theoretical process or a practice-based process: making, doing, writing, sketching or performing. This is an oversimplification, as there are overlaps between the two, but this division is a helpful device for understanding the design process.

\section{Design process: thinking/doing}

The abstract element of design is in thought processes, which can be performed alone or might form and reform during conversations and discussions amongst humans or interactions with nonhumans (Otto and Smith 2013). Humans can conceive of a design problem or a design solution and many things inbetween. Schon $(1992,11)$ describes how this abstract world of design operates 'the designer constructs the design world within which he/she sets the dimensions of his/her problem space, and invents the moves by which he/she attempts to find solutions'. This strategic abstraction of reality into an idealised and immaterial domain allows the freedom of creative thinking that is unencumbered from concrete constraints. It is only when those ideas meet back with the real world that a design can be finalised or, quite literally, be realised.

'Doing is designing for these people' (Frayling 1994, 2). 'These people' refers to expert designers and 'doing' refers to the blend of activities that includes sketches, drawing, measuring, modeling as well as thinking about the design. Design is not merely hypothetical work, it must be applied to a real-world phenomenon and that involves doing or performing an act. Design is the iterative process of practice-based actions and theoretical or reflective processes (Schon 1992). Wilson (1992) suggests that some forms of knowledge can only be accessed or generated through the hybridisation of abstraction and performance. In a design process, this can be understood as a form of tacit knowledge, the need for a practical aspect of knowledge production and dissemination (Collins 2010). Tacit knowledge is revealed through practice or performance (Pallasmaa 2009). In any form of participatory design some form of tacit practice is required alongside abstract processes. Nonhumans particularly come to the foreground as part of a performed or practice-based design process. Nonhumans have a complex inter-relationship with the design process, nonhumans can shape the thought process, nonhumans can be used to express ideas, nonhumans can test out design ideas (and often prove those ideas to be flawed or incorrect) and nonhumans can be an aid to generating new knowledge. Nonhumans participate in the design process through doing/acting.

These two forms of design, doing and thinking, are sometimes described as 'tactics' or 'strategies'. Derived from de Certeau's (1984) appropriation of the military terminology; strategies relate to the overall, long-term, abstract aim (and the means of achieving this). Tactics relates more to short-term contingent manoeuvres and practices in context, frequently without a coherent or explicit plan of action (Holmes 2007). Nonhumans participate in the design process through 'doing', which tends to be categorised as a tactic rather than a strategy of design. The dichotomy of strategic/tactical has been extended, particularly in relation to participatory urban design, to form a movement entitled 'tactical urbanism' (Pfeifer 2013). The implication being that tactics are good and strategies are bad (AAA/Peprav 2007; Fernandez and Mozas 2011; Lydon and Garcia 2015). Design practices related to 
action in the field, located in the here and now of lived experience are seen as a positive means of engaging in a design process (Rice, 2015). The practice of 'design through doing' is a mode of tactical design and invariably involves nonhuman participation.

\section{Summary of literature review}

The literature review articulates the participation of nonhumas in the design process. The first section outlines how nonhumans 'with sociology' are participants in the design process. Nonhumans and humans are actors in a network that can combine together to form a hybrid design collective. Nonhumans are part of the networkbuilding process of design: maintaining, strengthening or weakening alliances. An important aspect of the democratizing of participatory design is the transgression of boundaries and unnecessary dichotomies such that any design action is considered pertinent regardless of the status of the actor: human or nonhuman. Whilst the role of nonhumans is relatively under-examined in the field of participatory design, this is not the case in other disciplines where humans and nonhumans are afforded an equal and symmetrical status. Myriad actors ought to be considered equally for their various participatory actions. Nonhumans participate in design networks in three ways: by substituting human action, mediating human behaviour or communicating with humans. Nonhumans also play a part in/as the medium through which the design process is framed and developed - it is part of the language in which a design conversation is held. Nonhumans communicate with humans; sometimes they are made to write, scribble, sign and sometimes through sheer numbers akin to performing direct democracy. Nonhuman participation qua design activism is a form of democracy in action. The next section uses these themes through which nonhumans and humans participate in the design process to structure the findings.

\section{Findings}

The findings are based on an empirical study of a group of residents attempting to transform a previously derelict urban space into a 'community-garden'. The process of participatory design involves the design of the garden, and of community itself. The participatory design and community-garden require a large network of human and nonhumans. The network is an ongoing process of maintaining, adding, or subtracting actors. The case-study chosen is an appropriate example of the role of nonhumans in participatory design (Flyvbjerg 2001). A community-garden is a mixture of humans and nonhumans. The case study took place in the UK and fieldwork was undertaken over a period of five years. The author was involved in the process as a participant observer throughout the fieldwork (Mason 2002; Sanger 1996). The space is approximately one hundred square meters in size and is located in a predominantly residential area of a city. The area had been bombed during the Second World War and subsequently left derelict, mostly unused by humans other than children who occasionally played there and by various weeds. The derelict space had become a 'matter of concern' for the local residents. The space is unusual in that it is land to which the occupants have no legal claim, meaning that the community is technically trespassing when they access the site for gardening. This is referred to as 'guerilla gardening' (Reynolds 2009; Tracey 2007), whereby people garden on land 
they do not have the legal right to use. Regardless of the legal position pertaining to the ownership of the land, eventually the local residents began a process of clearing the space and converting it into a garden and this is where the fieldwork begins.

\section{'Autumn Gardening/Clearing Planting Session}

A REMINDER! You are invited to an Autumn clearing and gardening session... followed by coffee and croissants.

Bring: i) Grass seed to spread around.

ii) Bulbs and trowels to dig them in around the area...

iii) a rake to work the grass seed in

iv) A song to sing if you would like to, and a pot of yoghurt to eat with honey if that's what you'ld (sic) like!'

[Excerpt from a poster pinned to a lamppost at entrance to the fieldwork site].

\section{Introduction to findings}

The notice above is an excerpt of a hand written notice pinned to a lamppost at the entrance to the case-study area. This notice captures a rather typical series of events and activities that occur in the site for the empirical case-study. It serendipitously highlights many of the key factors that have formed part of the participatory design process. The process of designing a community-garden requires a network to be assembled: human participants do much of the work, equally needed are natural materials: grass, seeds, flowers and bulbs; the tools with which to garden: rakes and trowels; with some seemingly unrelated items: coffee, croissants, honey, yoghurt, songs; and not forgetting the sign (the poster) itself. The case-study examines this assemblage of human and nonhuman actors in the design of this community-garden network.

The poster highlights the production of a network, maintaining, removing and adding actors. The gardening session is one of many that serves to maintain the garden in an appropriate condition. Removal processes such as 'clearing' and weeding are proposed to cut links with unwanted actors. 'You are invited... bring' points to additive actions in relation to the network, for new human and nonhuman participants. This invitation also hints at the start of a democratic process; a democracy that ostensibly includes everyone. The sign also reveals the three mechanisms of nonhuman action in participatory design: substitution, mediation and communication. Firstly, the sign substitutes a human action; in lieu of a human verbally informing other local residents, the sign is now performing that role. Secondly, new nonhuman tools 'trowels ... rake' are proposed to mediate human action. Thirdly, the sign itself is a reminder of the capacity of nonhuman communication to humans. The findings are organised through the chronicling of these themes, firstly the production of networks: maintaining, removing and adding; then how nonhumans participate 
through the mechanisms of: substitution, replacement, and communication.

Democratic action is unearthed in the production of the garden and also how different forms of design strategies are evident, tactics and strategies. The findings conclude by examining how nonhumans configure the social.

\section{Assembling the garden}

Before the findings begin in earnest, it is necessary to contextualize the garden more generally. What exactly is a garden? A community-garden is a culturally-constructed quasi-natural entity (Berger 2006). Perhaps perversely, nature in an English garden is not very 'natural'. The flora we find today are the result of hundreds (sometimes thousands) of years of careful breeding and controlled genetic selection (Darwin, 2008). For example, flowers have been bred to have much larger blooms than occur naturally and grass has been domesticated into a more uniform, manageable variation (Mabey 2016). This community-garden is also not 'natural' as a consequence of its management; the formerly derelict space had been left to nature and consisted of various weeds but was not considered a garden. There are many dispositions, habits and practices particular to a community-garden that requires input from humans to maintain this particular socio-biological network. In this case-study, nature is a form of (English) garden; a culturally-specific spatial constellation of certain types of grasses, fauna and flowering plants and the absence of other flora (weeds) and fauna (pests).

A garden is a process and a network. A garden must be almost constantly prodded, cut, trimmed, weeded, cleared, planted and maintained. This process generates a heterogeneous network of: gardeners, flowers, trees, plants, fauna, soil, fences, walls, benches, wood chippings, signs, paths, bird-boxes and various other things. Simultaneously, it is important that a garden is not a network of weeds, pests, litter, vandals, dirt, decay, pollution etc. The design of a garden is the assembling of a network of desirable and workable associations and the disassociation from others. Two networks can be described in this case-study. Few of the original network become part of the community-garden; the majority of all nature (weeds) and the few humans (children) who frequented the derelict space had their ties cut. This network: children and weeds - form an unsuccessful network. In their place, an almost entirely new network is generated. The community-garden is comprised of adult residents and flowering plants - this is the successful network.

\section{Designing the community-garden: network addition and removal}

The first stage of this participatory design was to build a network of humans, i.e. to build a 'community'. Initially only a few local residents were involved; too few to claim to be a 'community' and too few to carry out all the gardening tasks necessary to maintain a garden of this size. These two factors meant that the scanty initial enthusiasts were forced to increase participation. Despite the many controversies in academia, there is not much debate amongst the residents about what 'community' specifically means in this context. The germane characteristic, in this instance, is that 'community' always connotes a group of humans, never a single person. The milieu of individuals, families, friends, strangers, enemies, adults and children must become 
a more organised network with a stable set of identities and relationships qua community. Humans provide the focal participants in forming, uniting and maintaining the community-garden network; however it would not be possible without the participation of nonhumans. Many of the 'participants' are nonhumans and they come in various guises: seeds, bulbs, trowels rakes, flowers, bees, birds, grass, fertilizer and pesticide. Nonhumans play a significant role in maintaining, adding to, or subtracting from, the garden. Spades are used to dig out the roots of weeds as well as bits of rubble and broken glass. Secateurs are used to remove parts of plants or cut unwanted plants such as ivy and bracken. The cutting of certain networks, physically and metaphorically, is part of the design process. Tools strengthen the garden network, for example trowels enable the planting of new flora and trellises support the fledgling plants. Fertilizer adds phosphates to the soil, which in turn nurtures growth of flora.

\section{Nonhuman participants substitute human action}

The first part of network building was to increase the quantity of humans in the network, in order to qualify as a community and to help distribute the work. The second part of network building was to use nonhumans to substitute, or act as a proxy for, human action. An example is how pesticides cut ties with unwanted networks of weeds (whilst reducing the need for human action). Instead of a human continuously and repeatedly weeding and removing unwanted plants; the use of pesticides delegates human action to a nonhuman actor. Pesticides are effective in cutting the alliance between the weeds and the soil. Pesticide has the advantage of working on unwanted alliances for an extended period of time; not just when a community member can be convinced to go and weed on a sunny afternoon. The weed-killer keeps on cutting unwanted links day and night for weeks and weeks (until the weed network is destroyed). In a reverse trajectory fertilizer acted to strengthen certain networks. Fertilizer was added to the flower beds and sometimes to the grassed areas to increase nutrients in the soil to help certain fauna flourish. This nonhuman strengthened the community-garden network for days and weeks without stopping or tiring. Rather than have gardeners perform the task of helping flowers survive; whether by careful tending to each flower physically or talking to the plants or even offering up a prayer to God for help - the fertilizer is a more reliable participant. Weedol and Growmore participated more in the design process than many of the human actors as they remained active for weeks and months, day and night; whereas human gardeners were considerably more intermittent in their activities.

\section{Nonhuman participants mediate human action}

A garden cannot be produced by people working with their bare hands; one cannot realistically dig holes, trim branches or remove brambles without any materials or implements. Nonhumans in the form of tools, whether animate or not, are imbricated with human action. There are many examples of the use of tools in the garden as mediators of human action. First, the (keenest) gardeners wore specific clothing in which to perform gardening; partly designed to deal with the mud and mess and partly to mediate the body: knee supports, metal toe protectors, gloves and tough snag-resistant materials to protect the skin from thorns and warmer/cooler fabrics to 
shelter from the weather dependent on the time of year. The gardeners also use a variety of specialized nonhuman devices in order to perform actions that would otherwise be impractical, unfeasible or impossible. There are simple tools: a spade for digging, a trowel for weeding, secateurs for cutting, a hose for watering, rakes for gathering as well as more complex devices: composters, lawn-mowers, pesticides, sprays, and wheelbarrows. All of these act as hybrid mediators for human action; sometimes making it easier, sometimes extending the range and power of humans; and sometimes giving new powers for human performance. There are myriad other examples of nonhumans mediating human behaviour, but not as tools. In the garden itself there are: benches, tables and a barbeque that enable or facilitate a modified mode of human action. There are more transitory examples: rugs and blankets are put down for picnics along with party cups and plates. Outside of the garden there is more administrative and organizational activity (related to the maintenance of the garden), for example: telephones, photocopiers, computers are used for communication. The living rooms of some residents are used for meetings and for post-gardening relaxation - along with 'coffee and croissants'. Nonhumans participate by mediating human action; most familiarly as gardening tools, but are manifest in many different ways, helping to modify, extend or augment human action.

\section{Nonhuman participant communication}

The sign at the entrance to the community-garden is a useful trope for the many roles a nonhuman can perform on behalf of a human. The same poster is reproduced as a leaflet and posted through nearby residents' letterboxes. The production of this poster, liberates several human actors from the obligation of having to inform (i.e. speak the information) to the many residents in a neighborhood. The poster frees up a considerable amount of time for humans who might otherwise have to attempt to disseminate the information orally. Whilst one volunteer still has to find some paper and a pen, it frees many others from, for example, having to stop at each residents' door and deliver that information by verbally repeating it to each of the hundreds of residents (which might take several days). This does not even consider the logistical issues concerning the pragmatics of trying to coordinate visits when people are actually at home to speak, in person, to residents (which might take several weeks). Instead the nonhuman leaflet, participates for hours and days, and performs the role of many, many humans. The above sign is one of many that plea for help from the community. The sign is what Latour describes as an object ' with sociology'. Signs entreat the community: 'please bring... ', 'please join us...', 'please could you help'. This begging for help is designed to act on the emotions of community, whether through feelings of guilt for not helping, or perhaps potential satisfaction from helping someone in need. The poster asks the community to bring along certain tools to help. The poster is aimed at attracting humans, but it surreptitiously also calls to nonhumans: trowels, seeds, bulbs, and rakes. The sign acts on humans and nonhumans, and the design of the community-garden network proceeds.

A community-garden is not an agriculturally productive space, there are no fruits or vegetables harvested; nor is it particularly useable for humans, much of the available space is taken up by flowers that are too delicate for humans to stand or sit on. The community-garden is a curious thing indeed, it consists of nature but is not natural; it produces no edible products and provides little useable space for human recreation; 
yet it takes considerable time and effort to maintain in this condition. The community-garden is, arguably, a sign; a sign to other humans. Communicating that there is a local community willing and able to maintain the space in this gardened condition (and conversely not the kind of community to leave it in a derelict state).

\section{Communication and Democracy in action}

The creation of the network: 'community-garden' is not as democratic as possible. Not everyone is included, some are 'in' and some are 'out'. The sign says: 'you are invited...' - the 'you' being the plural form, everyone and anyone is (ostensibly) invited to become a participant in the community and perform gardening. The leaflet is evidently aimed at humans, as they are the only participants who have the capacity to read. However, the leaflet is inadvertently disingenuous; it is effectively not inviting some humans: children who have not learned to read yet, people with poor eyesight and illiterate people. As we shall see, children are repeatedly disassociated from the community network by a number of different mechanisms. 'Coffee and croissants' and various other palatable nonhumans are used as bait to lure participants into the community network. These edibles are consumed in nearby livings rooms where the residents: meet, eat cake, drink coffee and discuss the community garden. The implied promise of comfortable sofas and carpeted floors, all pleasantly warmed via central heating, adorned with tasteful décor, not to mention the prospect of being able to have a nose around other peoples' houses encourage certain participants. Those who attend are mostly older, majority female, local residents. However, these living rooms also disassociate certain humans from the network. Children, particularly, are extirpated from the network; children do not usually drink coffee (and they are warned not to enter strangers' houses). Through the nonhuman space of a living room, a territory is created to keep some humans in, and others out. Nonhumans are participants in the reconfiguration of the social in specific sociospatial constellations.

The formerly derelict space must be accepted as a garden. Who makes this decision and who will speak on behalf of nature? The grass itself can say nothing directly, but is an illustration of how nonhumans participate. The decision lies with humans who are in a design conversation with nonhumans. Each blade of grass that can stand up and be counted acts like a voting system; rather like a form of direct democracy with each individual participating by raising their hand in the air. If the attempt to replace the bare earth or tangle of weeds with swathes of grass was unsuccessful, then this would be considered a 'no' vote. This form of representation or 'voting with one's feet' applies to the lack of the wrong type of nature (weeds). If there was the presence of weeds in the grassed areas or flowerbeds, then their presence could have been considered a vote against this being a garden. Weeds could not 'vote' by their absence due to the successful cutting of ties from the network. Conversely, the presence of each blade of grass is the equivalence of a 'yes' vote. The communitygarden network provided sufficient numbers of blades of grass (and flowers and trees and benches and paths and trellises etc) to represent a majority 'yes' vote. Grass qua nonhumans participate in the design process - they must acquiesce with the wishes of the gardeners and actually thrive for the process to be successful. Community accepting there is a garden is confirmation of this vote. Humans are in conversation with nonhumans using an ancient, but still valid, form of direct democracy. 


\section{Forms of design: strategies and tactics}

During the process of participatory design there are strategic and tactical modes of design in operation. In the various living rooms of nearby residents, strategic design is evident. It is here that strategic planning and abstract thinking about the design of the garden occurs. A number of different issues are discussed and proposed, for example; what flowers to plant in spring or autumn, how to target pesky weeds or whether to build another bench. These strategic sessions are relatively unfocussed and disorganized; multiple conversations occur simultaneously among different groups and subgroups of the community. Some of the strategies contradict others, whilst other strategies are ignored; some conversations repeat themselves over time. Much abstract design thinking is not acted upon, mostly due to lethargy or idleness. The process of participatory design is driven most forcefully by a few local residents. It is they who encourage other humans to attend - either directly or using signage. However they do not overly control the direction of the design of the garden, this is left to whomever turns up to actually carry out the gardening on a particular day. Strategic processes have minimal impact on the design development of the garden; most of the impact comes from design tactics. The design of the garden develops contingently over time by gardeners (and nonhumans) interacting on site, performing the various tasks of gardening. Whether to leave a particular plant, or remove it, is done in situ, at the discretion of each individual gardener. Designing through doing: gardening is a physical process that tactically and contingently interacts with the context. The dragging of a trowel across the contours of the land is just as much as a design tool as a dragging a pencil across paper. Design development occurred through the network of gardeners out doing the weeding, trimming, clearing and sundry other tasks. Working contingently with whatever new weed has appeared since the previous weeding session, deciding what to do with flowers that have wilted or died or how best to deal with England's changeable weather.

\section{Nonhumans configure the social}

The previous findings examined, in turn, the key themes that emerged in the literature review. Nonhumans are participating a number of different ways within the design process as part of the design team. The concluding part of the findings explore holistically the processes and mechanisms through which the nonhumans configure the social. The example takes place during the hot summer as the lawn lies parched; no longer green and lush, but dry and sickly yellow. Note: the grass will probably not die from lack of water, but looks unsightly and rather thin; furthermore healthier grass also helps prevent other weeds from securing a foothold. The parched grass communicates to the humans: 'I am thirsty'. In turn, the humans respond: 'grass - I will get you a drink'. In the short term, a rota is set up with various local residents each assigned a particular day of the week to do the watering. Order is imposed early on for this action: a rota is needed because humans must not randomly water - you might get lots of people at once (for example at weekends) and the disorganized humans might drown the lawn or nobody during the week as the disorganized humans let the lawn dry out. The ordering of the grass' requirements imposes on the social structure. These local residents carry water from their homes (in a variety of 
buckets, pots and watering cans) during the summer to water the grass (and other flora). Bob and Sue at number 32 do Wednesdays - they pop down after work; Margaret at number 12 goes each Friday morning after breakfast. The grass begins to configure human action and configures a new social organisation. Residents become waterers performing new daily and weekly rituals of behaviour.

In the longer term, the human waterers complain; it is too arduous a task to fetch water from their houses (many of the volunteers are quite elderly), and trying to water a lawn with a bucket is not ideal. Nonhumans are needed to substitute humans. A different strategy is devised; a water-supply (and hosepipe) is proposed. The watersupply is initially much harder to organise than the rota. An informal committee of volunteers form to deal with the various tasks required to deliver a new hosepipe and water supply. Funding (and therefore fund-raising activity) is required to pay for the new water-supply installation. The land is not owned by any person or organisation and the local Water Authority initially struggles to communicate with this unusual entity: Who to invoice? Who to bill? With whom to correspond? The local Water Authority requires invoicing accounts and financial transaction instructions - all of this requires: meetings, discussions, debates, arguments, frustrations, phonecalls, emails and photocopying. These actions and correspondences, initially related to the garden, now permeate into the nearby homes, and further afield onto the desks and computers of the Water Authority and local government. Gardeners wander the space discussing where to put the tap, standing where it might be (or not) - and acting out what they would do - using hands to mimic a tap and hosepipe and where to store the requisite equipment. Humans have to do drawings of where the tap will be. Representations of the space (a map) is produced - and a sketch of the proposed location is drawn on. The Water Authority has different plans - they (believe they) know where the nearest water main is (and where would be easiest for them). Eventually a compromise is made between the gardeners desired location, that of the local Water Authority and where the existing water mains actually is. Once the watersupply is installed, a hosepipe is attached and watering becomes a much easier task and it also enables a better conduit through which to deliver water to the parched grass in appropriate quantities and distribution. New watering rituals are enacted and performed in pursuance of the grass' thirst.

However the water supply also presents a quandary. Naughty children are considered a problem; so a lockable latch is put on the tap to stop the wasteful use of water by mischievous children (and others). This is a pre-emptive social configuring: cutting links with unwanted humans. The rota locks one social 'in'; the latch locks another social 'out'. Only those humans with the knowledge of the combination number can become waterers for the garden. The hosepipe/latch are not acting merely as a garden implement, they are having an effect on configuring new social networks. Grass 'speaking' to the humans initiated a process that involved myriad different humans and nonhumans, internal to and external from, the garden: the Water Authority, funding bodies, residents, photocopiers, telephones, plastic piping, perceptions of criminal/mischievous children (and mechanisms to lock them out) all in a new and complex network. The effect of the grass' thirst has unexpected effects on the social.

Some networks are strengthened, other networks are cut and new social configurations and rituals are performed. Nonhumans help to add to the network, the practice of watering requires a team of waterers to be enrolled into the network. The addition of (nonhuman) water helps additional grass grow during this period. 
Nonhumans substitutes humans, the water-supply replaces humans carrying water to site; similarly the lock replaces a human supervising the space against mischievous humans. Nonhumans prosthetize humans; the hosepipe enables new an hitherto impossible modes for delivering water to plants. Nonhumans communicate to humans - all this began by the grass telling the humans: 'I am thirsty'.

\section{Discussion}

The findings illustrate how nonhumans have participated in the design process. The empirical study highlights the specific relationships between humans and nonhumans in the design process. Nonhumans are active in strengthening or weakening networks. As the design progresses, certain networks are destroyed and removed and others are created or strengthened. Nonhumans do this in a number of ways; firstly by substituting humans often in an almost invisible process; for example, pesticide replaces gardeners in an indiscernible and unnoticed way. This substitution can free humans up to participate in other meaningful ways in the design process, or it can simply remove or displace human participants from the process. The relationship of this process to democracy is ambivalent; in some ways nonhuman substitution could enable greater democracy, but in other ways it could remove participatory action and potentially hinder the democratization process. Nonhumans also mediate in human actions; the various gardening implements help extend the capacity and affordance of human action; living rooms frame and curate the constituents of 'community'. Nonhuman mediation enabled, facilitated and/or extended human action. For example, most of the nonhuman devices used enabled the gardeners (particularly the elderly gardeners) to participate in the process in ways that would not be feasible without those devices. The use of nonhumans mediators was a generally positive force in the democratization of the design process. Nonhumans communicate with humans as part of the design process. Nonhumans act as the medium through which the design process is framed and developed - it is a part of the language in which the design conversation is held. Nonhumans through their sheer numbers perform communication akin to direct democracy. Nonhumans communicate in many ways; with each design scenario context dependent. In this case-study, the focus of design was very much a physical outcome - a community-garden. It is particularly through the mode of 'design through doing' that nonhumans contribute their most significant part. In other fields of participatory design when the outcome is less physical or material, it is likely that nonhumans play a lesser role in the design process.

\section{Conclusions}

Participatory design has an emphasis on increasing the network of participants and the level of participation. We see in this study that there is strengthening and building of a network - and a general increase in some participants, human and nonhuman, in the design of the community-garden. Croissants feed the community, whilst fertilizers feed flowers; the processes of network building are sometimes similar for humans and nonhumans. However, participation is not equally distributed; certain actors are fed whilst others are not. Network weakening and/or destruction is/are part of the design process. When nonhumans substitute humans, it can render human action invisible in the process. Similarly, when nonhumans mediate human behaviour 
it can alter the power balance resulting in some humans having more power than others. This imbalance of power is enacted partly through nonhumans, which again becomes invisible when the focus is solely on human participants. Nonhumans replace and mediate human behaviour - so it is important to make visible the role of nonhumans in the design process. If the focus is solely on human participants, then a piece of the picture is missing.

Participatory design requires sensitivity and awareness concerning who, or what, is included as a participant; and who, or what, is being excluded. The delegation of human tasks to nonhuman participants is often an invisible mechanism through which certain networks gather and maintain power (and exclude others in the process). If participatory design is to be a success, then there must be more equality in the process for all actors. Making the invisible more visible would be a desirable mechanism through which to make the participatory design process more democratic. Understanding how power operates and is manifest in the network, not just by focusing on humans, but also nonhumans, can be an important step in facilitating more successful participatory design.

\section{Disclosure statement}

No potential conflict of interest was reported by the author.

\section{References}

AAA/Peprav, eds. 2007. Urban Act - a Handbook for Alternative Practice. Paris: AAA.

Akama Yoko. 2015. "Being Awake to Ma: Designing in Between-ness as a Way of Becoming with.” CoDesign 11 (3-4): 262-274. doi: 10.1080/15710882.2015.1081243

Akrich, Madeleine, and Bruno Latour. 1992. "A Summary of a Convenient Vocabulary for the Semiotics of Human and Nonhuman Assemblies." In Shaping Technology/Building Society Studies in Sociotecnical Change, edited by Wiebe E. Bijke and John Law, 259-264. Cambridge, MA: The MIT Press.

Alger, Janet M. and Steven F. Alger. 1999. "Cat Culture, Human Culture: An Ethnographic Study of a Cat Shelter." Society and Animals 7 (3): 199-218.

Andersen, Lars Bo, Peter Danholt, Kim Halskov, Nicolai Brodersen Hansen, and Peter Lauritsen. 2015. "Participation as a Matter of Concern in Participatory Design." CoDesign 11 3-4.: 250-261. doi: 10.1080/15710882.2015.1081246.

Anusas, Mike and Tim Ingold. 2013. "Designing Environmental Relations: From Opacity to Textility." MIT Design Issues 29 (4): 58-69. doi: 10.1162/DESI_a_00230 Arblaster, Anthony. (1987) Democracy. Milton Keynes, Open University Press.

Bauman, Zygmunt. 2004. Wasted Lives: Modernity and its Outcasts. Cambridge: Polity Press. 
Bear, Christopher, and Sally Eden. 2011. "Thinking Like a Fish? Engaging with Nonhuman Difference Through Recreational Angling." Environment and Planning D: Society and Space 29 (2): 336-352.

Berger, Alan. 2006. Drosscape: Wasting Land Urban America. New York: Princeton Architectural Press.

Binder, Thomas, Eva Brandt, Pelle Ehn, and Joachim Halse. 2015. "Democratic design experiments: between parliament and laboratory." CoDesign 11 (3-4): 152165. doi: $10.1080 / 15710882.2015 .1081248$

Birke, Lynda, and Jo Hockenhull, eds. 2012. Crossing Boundaries: Investigating Human-Animal Relationships. Leiden: Brill.

Björgvinsson, Erling, Pelle Ehn and Per-Anders Hillgren. 2012. "Agonistic Participatory Design: Working with Marginalised Social Movements." CoDesign 8 (2-3): 127-144. doi: 10.1080/15710882.2012.672577

Brandt, Eva. Binder, Thomas. Sanders, Elizabeth. 2013. "Tools and Techniques: Ways to Engage Telling, Making and Enacting". In International Handbook of Participatory Design, edited by Jesper Simonsen and Toni Robertson, 145-181. New York: Routledge.

Bryant, Levi R. 2011. The Democracy of Objects. Michigan: Open Humanities Press.

Callon, Michel, Pierre Lascoumes, and Yannick, Barthe. 2011. Acting in an Uncertain World: An Essay on Technical Democracy, Inside Technology. Cambridge, MA: MIT Press.

Callon, Michel. and Law, John. 1982. "On Interests and Their Transformation: Enrolment and Counter-Enrolment”. Social Studies of Science. 12 (4): 615-625.

Callon, Michel. 1986. "Some Elements of a Sociology of Translation: Domestication of the Scallops and the Fishermen of St Brieuc Bay." In Power, Action and Belief: A New Sociology of Knowledge?, John Law, 1986. 196-233. London: Routledge.

Callon, Michel. 2004. "The Role of Hybrid Communities and Socio-Technical Arrangements in the Participatory Design." Journal of the Center for Information Studies 5 (3): 3-10.

Catt, Helena. 1999. Democracy in Practice. London: Routledge.

Collins, Harry. 2010. Tacit and Explicit Knowledge. University of Chicago Press.

Coole, D., and S. Samantha Frost, eds. 2010. The New Materialisms: Ontology, Agency, and Politics. Durham: Duke University Press.

Craft, Brock. 2013. Sketch-Ins: A Method for Participatory Design in TechnologyEnhanced Learning. In Handbook of Design in Educational Technology, edited by Luckin, Rosemary, Sadhana Puntambekar, Peter Goodyear, Barbara L. Grabowski, Joshua Underwood, and Niall Winters, 92-101. Abingdon: Routledge.

Crick, Bernard. 2002. Democracy: A Very Short Introduction. Oxford: Oxford University Press.

Darwin, Charles. 2008. On the Origin of the Species by Natural Selection. Herts, Wordsworth de Certeau, Michel. 1984. The Practice of Everyday Life. Berkeley: University of 
California Press.

DeLean Tolbert, Patrice M. Buzzanell, Carla B. Zoltowski, Antonette Cummings and Monica E. Cardella. 2016. "Giving and Responding to Feedback through

Visualisations in Design Critiques", CoDesign, 12 1-2.: 26-38. doi:

10.1080/15710882.2015.1135244

Derrida, Jacques. 2008. The Animal That Therefore I Am. New York: Fordham University Press.

Eco, Umberto. 1977. A Theory of Semiotics. Milan: Bompiani.

Fernandez Per, Aurora, and Javier Mozas, eds. 2011. Strategy and Tactics in Public Space. Alava: $A+T$ Architecture Publishers.

Ferrando, Francesca. 2013."Posthumanism, Transhumanism, Antihumanism, Metahumanism, and New Materialisms." Existenz 8 (2): 26-32.

Ferraro, Gary, and Susan Andreatta. 2011. Cultural Anthropology: An Applied Perspective. Belmont: Wadsworth.

Flyvbjerg, Bent. 2001. Making Social Science Matter: Why Social Inquiry Fails And How It Can Succeed Again. Cambridge: Cambridge University Press.

Ford, Martin. 2015. Rise of the Robots: Technology and the Threat of a Jobless Future. New York: Basic Books

Foucault, Michel. 2002. The Order of Things. Oxon: Routledge.

Fox, Rebekah. 2006. "Animal Behaviours, Post-Human Lives: Everyday Negotiations of the Animal-Human Divide in Pet-Keeping." Social and Cultural Geography 7 (4): 525-537.

Frayling, Christopher. 1994. "Monograph, Research in Art and Design." Royal College of Art Research Papers. 1 (1): 1-5.

Gunn, Wendy, Ton Otto, and Rachel Charlotte Smith, eds. 2013. Design Anthropology: Theory and Practice. London: Bloomsbury.

Habermas, Jurgen. 2006. "The Public Sphere: An Encyclopedia Article.” In Media and cultural studies: Keyworks, edited by, Meenakshi Gigi Durham and Douglas M. Kellner, 102-107. Oxford: Blackwell.

Haraway, Donna. 1991. Simians, Cyborgs, and Women. London: Free Association.

Haraway, Donna. 2000. How Like a Leaf: An Interview with Thyrza Nichols Goodeve. London: Routledge.

Haraway, Donna. 2003. The Companion Species Manifesto: Dogs, People and Significant Otherness. Chicago: Prickly Paradigm Press.

Haraway, Donna. 2008. When Species Meet. Minneapolis: University of Minnesota Press.

Harman, Graham. 2011. The Quadruple Object. Hants: Zero books.

Hayles, N. Katherine. 2008. How We Became Posthuman: Virtual Bodies in Cybernetics, Literature, and Informatics. Chicago: University of Chicago Press.

Held, David. 2006. Models of Democracy. Cambridge: Polity Press.

Herbrechter, Stefan. 2013. Posthumanism: A Critical Analysis. London, Bloomsbury. 
Holmes, Brian. 2007. Do-It-Yourself Geopolitics: Map of the World Upside Down. In Urban Act - a Handbook for Alternative Practice, edited by AAA/Peprav, 300-306. Paris: AAA.

Jönsson, Li. and Lensskjold, Tau Ulav. (2015) "Stakes at the Edge of Participation: Where Words and Things are the Entirely Serious Title of a Problem". Nordes 1 (6): $1-9$.

Kensing, Finn, and Jeanette Blomberg. 1998. "Participatory Design: Issues and Concerns." Computer Supported Cooperative Work (CSCW) 7(3-4): 167-185.

Kensing, Finn, and Joan Greenbaum. 2012. Heritage: Having a Say. In Routledge International Handbook of Participatory Design, edited by Jesper Simonsen and Toni Robertson, 21-36. London: Routledge.

Latour, Bruno. and Steve Woolgar. 1986. Laboratory life. The Construction of Scientific Facts. New Jersey: Princeton University Press.

Latour, Bruno. 1987. Science in Action. Cambridge, Mass.: Harvard University Press.

Latour, Bruno. 1992. Where are the Missing Masses? Sociology of a Few Mundane Artefacts. In: Shaping Technology, Building Society: Studies in Sociotechnical Change, edited by Wiebe Bijker and John Law, 225-258. Cambridge, Mass.: Cambridge University Press.

Latour, Bruno. 1999 Pandora's Hope: Essays on the Reality of Science Studies. Cambridge MA: Harvard University Press.

Latour, Bruno. 2005a. Reassembling the Social: An Introduction to Actor-NetworkTheory. Oxford: Oxford University Press.

Latour, Bruno. 2005b. "From Realpolitik to Dingpolitik or How to Make Things Public." In Making Things Public: Atmospheres of Democracy, edited by Bruno Latour and Peter Weibel, 14-43. Cambridge: MIT.

Law, John and Annemarie Mol. 1995. "Notes on Materiality and Sociality." The Sociological Review 43 (2): 274-294.

Law, John. 2004. After Method: Mess in Social Science Research. London: Routledge.

Law, John. 2009. "Actor network theory and material semiotics." In The new Blackwell companion to social theory, edited by Bryan S. Turner, 141-158. Oxford: Blackwell.

Lawson, Bryan. 2005. How Designers Think: The Design Process Demystified. London: Routledge.

Lindstrom, Kristina, and Asa Stahl. 2012. "Making Private Matters Public in Temporary Assemblies." CoDesign 8 (2-3): 145-161. doi: http://dx.doi.org/10.1080/15710882.2012.672578.

Lydon, Mike. and Anthony Garcia. 2015. Tactical Urbanism: Short-term Action for Long-term Change. Washington: Island Press.

Mason, Jennifer. 2002. Qualitative Researching. London: Sage.

Mabey, Richard. 2016. The Cabaret of Plants: Forty Thousand Years of Plant Life and the Human Imagination. London: Profile Books.

Mouffe, Chantal. 2000. The Democratic Paradox. London: Verso. 
Muller, Michael J. 2007. "Participatory Design: The Third Space in HCI." In HumanComputer Interaction: Development Process, edited by Andrew Sears and Julie A. Jacko, 165-185. Boca Raton, CRC Press.

Nayar, Pramod, K. 2013. Posthumanism. London, Polity.

Otto, Ton, and Rachel Charlotte Smith. 2013. "Design Anthropology: A Distinct Style of Knowing." In Design Anthropology: Theory and Practice. Edited by Wendy Gunn, Ton Otto and Rachel Charlotte Smith, 1-29. London: Bloomsbury.

Pallasmaa, Juhani. 2009. The Thinking Hand: Existential and Embodied Wisdom in Architecture. West Sussex: John Wiley and Sons.

Palmås, Karl, and Otto von Busch. 2015. "Quasi-Quisling: Co-Design and the Assembly of Collaborateurs." CoDesign 11 (3-4): 236-249. doi: 10.1080/15710882.2015.1081247

Pedersen, Jens. 2015. "War and peace in Codesign." CoDesign 12 (3): 1-14. doi: $10.1080 / 15710882.2015 .1112813$

Pfeifer, Laura. 2013. The Planner's Guide to Tactical Urbanism Accessed 12 September 2016.

https://reginaurbanecology.files.wordpress.com/2013/10/tuguide1.pdf

Rancière, Jacques. 2015. Dissensus: On Politics and Aesthetics. London: Bloomsbury.

Rawls, John. 2005. Political Liberalism. New York: Columbia University Press.

Rendell, Jane. 2004. Architectural Research and Disciplinarity. Arq. 8 (2): 141-147.

Reynolds, Richard. 2009. On Guerrilla Gardening: A Handbook for Gardening without Boundaries. London: Bloomsbury.

Rice, Louis. 2013. "Occupied Space." AD (Architectural Design), The Architecture of Transgression 82 (1): 70-75.

Rice, Louis. 2015. Informal Architecture/s. In Transgression: Towards an Expanded Field of Architecture, edited by Louis Rice and David Littlefield, 87-101. London: Routledge.

Robertson, Toni and Jesper Simonsen. 2012. Participatory Design: An Introduction. In Routledge International Handbook of Participatory Design, edited by Jesper Simonsen and Toni Robertson, 1-18. London: Routledge.

Sanders, Elizabeth B. N. and Pieter Jan Stappers. 2008. "Co-Creation and the New Landscapes of Design." Co-design 4 (1): 5-18. doi: 10.1080/15710880701875068.

Sanders, Elizabeth, B. 2000. "Generative Tools for Co-Designing." In Collaborative Design, edited by Stephen A.R. Scrivener, Linden J. Ball and Andree Woodcock, 312. London: Springer-Verlag.

Sanger, Jack. 1996. The Compleat Observer? A Field Research Guide to Observation. London: Falmer Press.

Sanoff, Henry. 2005. "Community Participation in Riverfront Development." CoDesign 1 (1): 61-78. doi: 10.1080/15710880512331326022.

Sayes, Edwin. 2014. "Actor-Network Theory and Methodology: Just What Does it Mean to say that Nonhumans have Agency?" Social Studies of Science 44 (1): 134149. 
Schoffelen, Jessica, Sandy Claes, Liesbeth Huybrechts, Sarah Martens, Alvin Chua and Andrew Vande Moere. 2015. "Visualising Things. Perspectives on How to Make Things Public through Visualization." CoDesign 11 (3-4): 179-192. doi:

10.1080/15710882.2015.1081240.

Schoffelen, Jessica, and Liesbeth Huybrechts. 2013. "Sharing is Caring: Sharing and Documenting Complex Participatory Projects to Enable Generative Participation."

Interaction Design and Architecture(s) Journal: Special Issue Culture of Participation. 1 (18): 9-2.

Schon, Donald. 1992. The Reflective Practitioner: How Professionals Think in Practice NY: Basic Books.

Schumacher, Patrik. 2016. "Advancing Social Functionality via Agent-Based Parametric Semiology." Architectural Design 86 (2): 108-113.

Serres, Michel. 1980. Hermes: Le Passage Du Nord-Ouest [Hermes: The Northwest Passage]. Paris: Editions de Minuit.

Serres, Michel. 1995. Angels : A Modern Myth. Paris: Flammarion.

Serres, Michel. 2007. The Parasite. Minneapolis: University of Minnesota.

Storni, Cristiano. 2015. "Notes on ANT for Designers: Ontological, Methodological and Epistemological Turn in Collaborative Design." CoDesign 11 (3-4): 166-178. doi: $10.1080 / 15710882.2015 .1081242$.

Stuedahl, Dagny, and Ole Smordal. 2015. "Matters of Becoming: Experimental Zones for Making Museums Public with Social Media." CoDesign 11 (3-4): 193-207. doi: 10.1080/15710882.2015.1081245.

Tracey, David. 2007. Guerrilla Gardening: A Manualfesto. Gabriola Island: New Society Publishers.

Whatmore, Sarah. 2002. Hybrid Geographies: Natures, Cultures, Spaces. London: Sage.

Wilson, F. 1992. The Human Hand: How Its Use Shapes the Brain, Language, and Human Culture. NY: Pantheon Books.

Wynn, Thomas. 2002. "Tools and Tool Behavior." In Companion Encyclopedia of Anthropology, edited by Tim Ingold, 133-61. London: Routledge. 